\title{
Insertion of Cochlear Implant Electrodes through Round Window Membranes: It's Accessibility in Pediatric Population
}

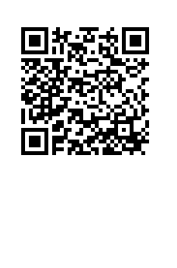

\author{
Iqbal Javed Khan ${ }^{1}$, Montasir Junaid ${ }^{2 *}$, Nadeem Mukhtar ${ }^{1}$, Asim Iqbal ${ }^{2}$, Ahsan Danish ${ }^{3}$ and Sadaf Qadeer Ahmed ${ }^{4}$ \\ ${ }^{1}$ Consultant Audiologist \& Cochlear Implant Surgeon, Pakistan Cochlear implant Program, Pakistan
}

${ }^{2}$ Consultant ORL, H\&N surgery, Armed Forces Hospital Southern Region, KSA

${ }^{3}$ Audiology and speech pathology, Coordinator Pakistan Cochlear implant Program, Pakistan

${ }^{4}$ Assistant Professor Otolaryngology-Head and Neck Surgery, Sir Syed College of Medical Sciences for Girls, Pakistan

Submission: August 08, 2020; Published: August 26, 2020

*Corresponding author: Montasir Junaid, Consultant ORL, H\&N surgery, Armed Forces Hospital Southern Region, KSA

\section{Abstract}

Introduction: For infants and children with severe to profound hearing impairment, cochlear implantation is the widely accepted surgery of choice. There has been a recent shift of electrode array insertion from bony cochleostomy to round window membrane (RWM) insertion. Round window membrane is strategically placed which could be accessed after an optimal post tympanotomy. St. Thomas hospital (STH) classification is used to evaluate the accessibility of RWM insertion of electrode array and can be classified as Types I, IIa, IIb and III. In type I RWM is $100 \%$ visible and insertion is straight forward while in type III RWM is not visualized at all and a bony cochleostomy is undertaken.

Material \& Methods: A total of 190 patients were included with minimum age of 1.5 years and maximum of 4.1 with mean of 2.76 , There were $48.2 \%$ males and $50.3 \%$ females in the group. Children with diagnosed syndromes or age more than 4.5 were not included in study.

Results: The cause of hearing loss in majority of cases was unknown (53.7\%) followed by low birth weight (14.7\%), maternal infections (12.6\%), meningitis (6.3\%), birth asphyxia and jaundice (5.3\%) and non-inherited congenital (2.1\%) All the type III patients underwent bony cochleostomies $(2.1 \%)$ while simple round window insertions were $65.3 \%$ (32.2\% in Type I, $54.8 \%$ in type II a and $12.9 \%$ in Type II b) and $32.6 \%$ underwent extended round window insertion. (33.8\% in type II and $66.1 \%$ in Type II b).

Conclusion: STH classification is an easy way to assess the accessibility of RWM insertion in patients planned for cochlear implantation provided that a proper posterior tympanotomy has been undertaken.

Keywords: Sensorineural hearing loss; Facial recess; CI electrode; Cochlea; Promontory cochleostomy; Round window membrane; Ear infection; Minimal perilymph loss; Acoustic trauma

\section{Introduction}

In Recent years cochlear Implantation has become a highly efficient therapeutic procedure of choice for severe to profound sensorineural hearing loss, not responding to other forms of augmentation devices [1-4]. The classical approach for inserting CI electrode into the cochlea is through the facial recess opening which itself is limited by both facial and chorda tympani nerve $[5,6]$. Electrode insertion can be achieved through bony cochleostomy located anterior inferior to round window at basal turn of cochlea or through the round window membrane itself $[2,7]$. Though Only $30 \%$ of round window is visualized through facial recess without further drilling (to decrease overhangs) [8]. Recent years show there has been a paradigm shift for electrode insertion from standard promontory cochleostomy to round window membrane insertion [9-11].

Despite the obvious advantages, associated with round window membrane electrode insertion, such as reducing acoustic trauma due to decrease amount of drilling required, minimal perilymph loss, faster healing , decrease risk of ear infection, [8] availability of wider stimulation surface area length by $2 \mathrm{~mm}$ [2] since conventional bony cochleostomy leaves some part of spiral 
lamina out of stimulation. Authors agree round window approach may lead to destruction of residual hearing, while insertion of electrodes and approach to round window membrane itself can be quite challenging due to variable adjacent anatomy $[2,5]$ and bony overhangs of round window niche which obscure visibility but drilling the overhangs can increase the visibility by $1.5-3$ times [8].

The widest dissection of facial recess itself leads to complication such as damage to bony annulus, chorda tympani, and facial nerve, while accessibility of RWM is better in adults than children with later RWM situated at a more obtuse angle when compared with adults [12]. To overcome challenges faced by surgeon for insertion of electrode via Round window membrane ST Thomas Hospital classification system [13] was introduced as an intraoperative classification and guide for surgeons to access RWM after widest post Tympanotomy. Our objective was to assess the STH classification system in pediatric population, its usefulness in aiding surgeons to correctly select route of electrode insertion into the cochlea (RWM or Bony Cochleostomy).

\section{Material and Methods}

\section{Study design}

This was a prospective, observational cohort study on a consecutive 190 pediatric patients (aged 1.5 years -3.5 years) who presented and registered with Pakistan Cochlear implant program (A charitable pediatric cochlear implant Organization since the year 2000) over a period of two years (Jan 2014 to Jan 2016). All Cases were performed in a tertiary referral center by single senior surgeon after ethical approval was obtained from institutional approval committee.

\section{Data collecting procedure}

All patients underwent mandatory Pre-Anesthesia assessment, Hearing assessment (ABR), C.T scan and MRI scan for internal auditory meatus and temporal bone prior to surgery. Patients with active ear or nose infection and suspected anomaly of temporal bone or revision surgery were excluded from the cohort to reduce bias. Patient data was collected in a questionnaire for general parameters such as age, gender, side of implant and intraoperative details for classification as observed by the single senior surgeon and post-operative complications. Data was analyzed using updated version of SPSS.

\section{Intra-operative details}

The single senior surgeon performed the cortical mastoidectomy as text with intent to insert electrode via Round window through post tympanotomy. Maximum dissection was carried out preserving only a thin bone over chorda tympani and facial nerve, post canal wall, bony annulus, superiorly incus buttress and inferiorly chordo-facial angle were also preserved in its entirety (optimal posterior tympanotomy). Through this optimal posterior tympanotomy and without breaching the RWM annulus the bony overhangs were dissected and RWM was observed and staged (STH classification) according to its ease of accessibility for the electrode insertion. The best route (RWM / Bony Cochleostomy) for electrode insertion was decided by same senior surgeon after applying STH staging system.

\section{The STH classification system}

\section{STH Classification}

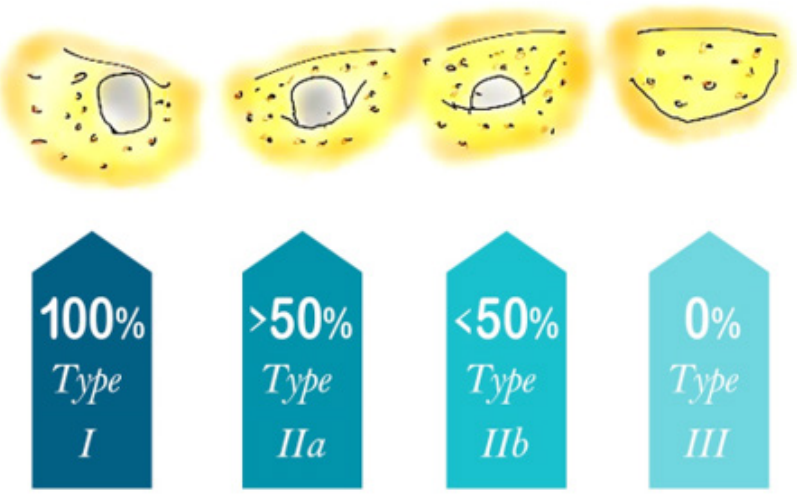

Figure 1: STH classification according to round window membrane exposure after optimal posterior tympanotomy.

First published in 2007 [13] and based on "Optimal Post Tympanotomy" or "A wide Post Tympanotomy" after cortical mastoidectomy to visualize RWM niche (as Described earlier).
Description of STH classification system along with type of electrode insertion (RWM /Bony Cochleostomy) given in Table 1 \& Figure 1 . 
Table 1: STH classification system along with type of electrode insertion.

\begin{tabular}{|c|c|c|c|c|}
\hline Type of RWM & Type I & Type II & & Type III \\
\hline & & Type II a & Type II b & \\
\hline Exposure & $100 \%$ & $>50 \%$ but $<100 \%$ & $>0 \%$ but $<50 \%$ & $0 \%$ \\
\hline Description & $\begin{array}{l}\text { After optimal post } \\
\text { tympanotomy }\end{array}$ & $\begin{array}{l}\text { Ant inferior extension of } \\
\text { bony RWM required for } \\
\text { some cases }\end{array}$ & $\begin{array}{l}\text { Ant inferior extension of bony } \\
\text { RWM required for some cases }\end{array}$ & $\begin{array}{c}\text { Even after optimal post tympanoto- } \\
\text { my and removing all possible bony } \\
\text { overhangs }\end{array}$ \\
\hline Type of insertion & $\begin{array}{l}\text { Round window } \\
\text { membrane }\end{array}$ & Round window membrane & $\begin{array}{c}\text { Round window membrane } \mathrm{V} / \mathrm{S} \\
\text { Bony cochleostomy }\end{array}$ & Bony cochleostomy \\
\hline
\end{tabular}

In Type III cases the placement of RWM is closer to facial nerve, which needs conventional bony cochleostomy (done anterior inferior to RWM near Basal Turn). While Type I and II a i.e $>50 \%$ RWM visible membranous insertion of electrode is advised, whereas in Type II b cases where there is $<50 \%$ RWM visibility both bony and membranous electrode insertions can be undertaken. It has been mentioned in literature and observed by senior surgeon that for some cases of IIb an anterior inferior extension of bony RW by $1-2 \mathrm{~mm}$ was required to place the electrode with ease.

\section{Results}

The mean age of the patients was 2.77, out of them $51.05 \%$ were females and $48 \%$ were males. Among the causes of hearing loss, the most common was congenital/non syndromic (53.68\%), followed by low birth weight $(14.74 \%)$ and maternal infections (12.63\%) (Table 2). The mean age of the patients was 2.77 , out of them $51.05 \%$ were females and $48 \%$ were males. Among the causes of hearing loss, the most common was congenital/non syndromic $(53.68 \%)$, followed by low birth weight $(14.74 \%)$ and maternal infections (12.63\%) (Table 2). Round window membrane exposure was $47 \%$ in type $2 \mathrm{a}$ followed by type $2 \mathrm{~b}$ (30\%), type $1(21 \%)$ and least in type $3(2 \%)$ (Figure 2$)$. Electrode was inserted in round window in $65 \%$ of patients while in $33 \%$ extended round window insertion was done and in $2 \%$ patients bony cochleostomy was performed (Figure 3). All type 1 had round window insertion of electrode while in type $2 \mathrm{a}$ and type $2 \mathrm{~b}$ had $76.4 \%$ and $28.1 \%$ of electrode insertion (Figure 4 ). Rate of wound infection was $1.6 \%$ and in $98.4 \%$ of cases no complication was observed.

Table 2: Patient Characteristics.

\begin{tabular}{|c|c|c|c|}
\hline & & Mean & SD \\
\hline Age & & 2.77 & $0.61+/-$ \\
\hline \multirow{3}{*}{ Gender } & & $\mathbf{n}$ & $\%$ \\
\hline & Male & 93 & 48.95 \\
\hline & Female & 97 & 51.05 \\
\hline \multirow{7}{*}{ Cause of Hearing Loss } & Non-inherited congenital & 4 & 2.11 \\
\hline & Maternal infection & 24 & 12.63 \\
\hline & Meningitis & 12 & 6.32 \\
\hline & Hyperbiliburemia & 10 & 5.26 \\
\hline & Low birth weight & 28 & 14.74 \\
\hline & Birth Asphyxia & 10 & 5.26 \\
\hline & Congenital/ Non-Syndromic & 102 & 53.68 \\
\hline
\end{tabular}




\section{Round Window Membrane Exposure}

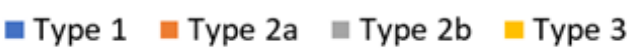

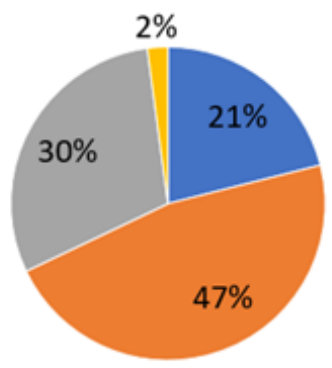

Figure 2: Round Window Membrane Exposure.

\section{Electrode Insertion}

- Round Window Insertion

- Extended Round Window Insertion

Bony Chochleostomy

$2 \%$

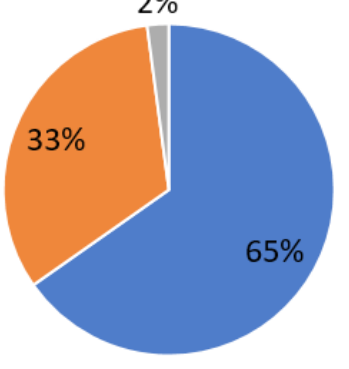

Figure 3: Electrode Insertion.

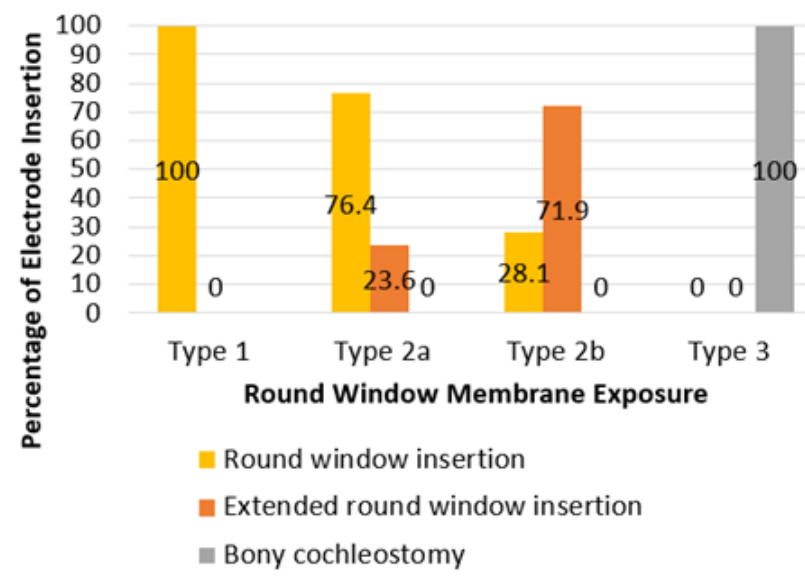

Figure 4: Frequency of Electrode Insertion by Round Window Membrane Exposure. 


\section{Global Journal of Otolaryngology}

\section{Discussion}

The round window membrane and niche both have highly variable morphology, since RWM is a constant landmark in Cochlear implant surgery, the operating surgeon should be aware of its morphological variation and anatomical relationships in order to introduce the electrode safely and successfully [2-7]. A Singla [14] described the shape of RW as oval, Round, Triangular, coma, quadrangular and pear shape with oval being the most common (20\%) and pear shape being the least ( $2 \%$ only). While debate has been there regarding change in the shape of RWM from round to triangular form [15] while average height and width were calculated $1.62+/-0.77 \mathrm{~mm}-1.15+/-0.39 \mathrm{~mm}$ respectively, while extremely narrow RW makes electrode insertion difficult and further drilling is usually required [14].

Similarly, anatomical structures surrounding the niche can play a crucial role in electrode insertion such as exostosis near entrance of niche or high jugular dome. As the walls surrounding the niche are developed by both membranous and chondral bones thus do not grow in an equal fashion while this unequal growth pattern may lead to modification of RWM entrance itself [15]. On Further removing the bony overhang of niche a surgeon may increase the visibility of RWM by $1.5-3$ while further drilling of ant inf tip of niche may aid easy electrode insertion along main axis of scale tympani and avoids injury to intracochlear structures [8].

Our Study included pediatric population only and all type III cases $(2 \%)$ required a conventional bony cochleostomy while greatest numbers of our patients fall into type IIa category $(47 \%)$ with $76.4 \%$ round window insertion and extended round window approach in $23.6 \%$. Though in our series the number of type 1 cases was $21 \%$ only, the insertion of electrode in all of these cases was simple round window insertion (100\%) when compared to Leong et al in which both Pediatric and adult cohort was included, they reported Type I and IIa (Adults: 89\%, Pediatrics:78\%) to be a more common occurrence in their study group. The most common STH classification type in their pediatric group was type I (46\%) while in our study it was type IIa (47\%). Further in the same study, type IIb and III were found to be twice as more common in the pediatric population than an adult. They proposed an increase chance of extended round window insertion and bony Cochleostomy in Pediatric Population which may be partly due to cochlear orientation at a more obtuse angle than adults; none the less all type III cases (pediatric or adult) required bony cochleostomy [12].

Till date, no classification system is available as a standard intraoperative guide to help the ontological surgeon decide about the best possible route for electrode insertion in Cochlear implant surgery. The authors have found STH classification system to be a useful tool in helping the surgeon to decide RWM insertion versus Conventional Bony Cochleostomy. The authors found the
STH system to be an evolving anatomical exercise and results depending on operating surgeon and his orientation with variants of mastoid anatomy. Further studies in this regard with a larger cohort and comparing results with that of adult anatomy will be useful.

\section{Conclusion}

Though choosing RWM over Conventional Bony Cochleostomy is purely surgeons' decision and partly on the expertise available. The STH classification system does aid in visualization and accessibility of RWM and is a useful tool to guide surgeon in selecting optimal route for electrode insertion in pediatric population.

\section{References}

1. Clark G, YC Tong (1981) Multiple-electrode cochlear implant for profound or total hearing loss: a review. Med J Aust 1: 428-496.

2. Paprocki A, Biskup B, Kozlowska K, Kuniszyk A, Bein D, etal. (2004) The topographical anatomy of the round window and related structures for the purpose of cochlear implant surgery. Folia Morphol (Warsz) 63: 309-312.

3. Papsin BC, Gordon KA (2007) Cochlear implants for children with severe to profound hearing loss. N Engl J Med 357: 2380-2387.

4. Pakdaman MN, Herrmann BS, Curtin HD, Beek KingJ V, Lee DJ (2012) Cochlear implantation in children with anomalous Cochleovestibular Anatomy: A systemic review. Otolaryngol Head Neck Surg 146(2): 180190.

5. Hamamoto M, Murakami G, Kataura A (200) Topographicl relationships among the facial nerve, chorda tympani nerve, and round window with special reference to the approach route for cochlear implant surgery. Clin Anat 13(4): 251-256.

6. Bielamowicz SA, Newton J Coker, Herman A Jenkins, Makoto Igarashi (1988) Surgical dimensions of the facial recess in adults and children. Arch Otolaryngol Head and Neck Surg 114(5): 534-537.

7. Briggs RJ, Tykocinski M, Xu J, Risi F, Svehla M, et al. (2006) Comparision of round window and cochleostomy approaches with a prototype hearing preservation electrode. Audiol Neurotol 11(sup1): 42-48.

8. Roland PS, Wright CG, Isaacson B (2007) Cochlear implant electrode insertion: The Round window revisited. Laryngoscope 117(8): 13971402.

9. Adunka O, Unkelbach M, Mack K, Markus Hambek, Wolfgang Gstoettner, et al. (2004) Cochlear implantation via the round window membrane minimizes trauma to cochlear structures: a histologically controlled insertion study. Acta Otolaryngol 124: 807-812.

10. Adunka OF, Buchman CA (2007) Scala tympani cochleostomy I: results of a survey. Laryngoscope 117: 2187-2194.

11. Gudis D A, Montes M, Bigelow DC, Ruckenstein MJ (2012) The Round Window: Is it the "Cochleostomy" of Choice? Experience in 130 Consecutive Cochlear ImplantsOtol Neurotol 33: 1497-1501.

12. Leong A C, Jiang D, Agger A, Fitzgerald O Connor A (2013) Evaluation of Round window accessibility to cochlear implant insertion. Eur arch Otorhinolaryngology 270: 1237-1242.

13. Jiang D, Fitzgerald O Connor A (2007) The Assessment of the access to round window approach through a posterior tympanotomy: A practical classification. In: Presented at the $26^{\text {th }}$ Politzer Society Meeting, Cleveland, USA, pp. 13-16. 
14. Singla A, Sahni D, Gupta AK, Loukas M, Aggarwal A (2014) Surgical Anatomy of Round window and its implications for cochlear implantation. Clinical Anatimy 27: 331-336.
15. Toth M, Alpar A, Patonay L, Olah I (2006) Development and surgical anatomy of the round window niche. Ann Anat 188: 93-101.

\section{Your next submission with Juniper Publishers} will reach you the below assets

- Quality Editorial service

- Swift Peer Review

- Reprints availability

- E-prints Service

- Manuscript Podcast for convenient understanding

- Global attainment for your research

- Manuscript accessibility in different formats ( Pdf, E-pub, Full Text, Audio)

- Unceasing customer service

Track the below URL for one-step submission https://juniperpublishers.com/online-submission.php 